OPEN ACCESS

Edited by:

Yulin Ge,

New York University, United States

Reviewed by:

Bo Gao,

Affiliated Hospital of Guizhou Medical

University, China

Mark S. Bolding,

University of Alabama at Birmingham,

United States

*Correspondence:

Zhiliang Wei

zhiliang.wei@jhu.edu

Specialty section:

This article was submitted to Applied Neuroimaging,

a section of the journal

Frontiers in Neurology

Received: 15 March 2020 Accepted: 15 May 2020

Published: 12 June 2020

Citation:

Wei Z, Chen L, Hou X, van Zijl PCM,

$X u J$ and $L u H(2020)$ Age-Related Alterations in Brain Perfusion, Venous

Oxygenation, and Oxygen Metabolic

Rate of Mice: A 17-Month Longitudinal

MRI Study. Front. Neurol. 11:559.

doi: 10.3389/fneur.2020.00559

\section{Age-Related Alterations in Brain Perfusion, Venous Oxygenation, and Oxygen Metabolic Rate of Mice: A 17-Month Longitudinal MRI Study}

\author{
Zhiliang Wei ${ }^{1,2 *}$, Lin Chen ${ }^{1,2}$, Xirui Hou ${ }^{3}$, Peter C. M. van Zij1 ${ }^{1,2}$, Jiadi $X u^{1,2}$ and \\ Hanzhang $\mathrm{Lu}^{1,2,3}$ \\ ${ }^{1}$ Russell H. Morgan Department of Radiology and Radiological Science, Johns Hopkins University School of Medicine, \\ Baltimore, MA, United States, ${ }^{2}$ F. M. Kirby Research Center for Functional Brain Imaging, Kennedy Krieger Research \\ Institute, Baltimore, MA, United States, ${ }^{3}$ Department of Biomedical Engineering, Johns Hopkins University School of \\ Medicine, Baltimore, MA, United States
}

Background: Characterization of physiological parameters of the aging brain, such as perfusion and brain metabolism, is important for understanding brain function and diseases. Aging studies on human brain have mostly been based on the cross-sectional design, while the few longitudinal studies used relatively short follow-up time compared to the lifespan.

Objectives: To determine the longitudinal time courses of cerebral physiological parameters across the adult lifespan in mice.

Methods: The present work examined longitudinal changes in cerebral blood flow (CBF), cerebral venous oxygenation $\left(\mathrm{Y}_{\mathrm{v}}\right)$, and cerebral metabolic rate of oxygen $\left(\mathrm{CMRO}_{2}\right)$ using MRI in healthy C57BL/6 mice from 3 to 20 months of age. Each mouse received 16 imaging sessions at an $\sim 1$-month interval.

Results: Significant increases with age were observed in $\mathrm{CBF}(p=0.017)$ and $\mathrm{CMRO}_{2}$ $(p<0.001)$. Meanwhile, $Y_{v}$ revealed a significant decrease $(p=0.002)$ with a non-linear pattern $(p=0.013)$. The rate of change was $0.87,2.26$, and $-0.24 \%$ per month for CBF, $\mathrm{CMRO} 2$, and $Y_{v}$, respectively. On the other hand, systemic parameters such as heart rate did not show a significant age dependence $(p=0.47)$. No white-matter-hyperintensities $(\mathrm{WMH})$ were observed on the $\mathrm{T}_{2}$-weighted image at any age of the mice.

Conclusion: With age, the mouse brain revealed an increase in oxygen consumption. This observation is consistent with previous findings in humans using a cross-sectional design and suggests a degradation of the brain's energy production or utilization machinery. Cerebral perfusion remains relatively intact in aged mice, at least until 20 months of age, consistent with the absence of $\mathrm{WMH}$ in mice.

Keywords: aging, cerebral blood flow, cerebral metabolic rate of oxygen, longitudinal, C57BL/6 


\section{INTRODUCTION}

Characterization of neurobiological changes in the aging brain is important in understanding brain function, neurodegeneration, and possibly dementia (1-3). While brain anatomical and structural measures have been studied extensively and generally reveal degradations with age (4-8), functional and physiological changes are more complex and have yielded more intriguing observations (9-12). For example, many studies on human brain aging have shown that fMRI signals in response to tasks are paradoxically greater in old than in young participants (13-16). Furthermore, when measuring basal brain oxygen metabolic rate as a surrogate marker of neural activity at rest, several studies have suggested that the brain of an older individual consumes more oxygen (per unit volume tissue) compared to younger individuals $(10,17)$. These findings have led to several interesting hypotheses such as a compensatory increase in neural activity in older individuals $(10,18)$, a diminishment of specificity in brain activation (19), or a reduced computational efficiency in neural circuits (20).

However, a shared limitation of these reports lies in their cross-sectional experimental design without the tracking of same subjects over time. There are also concerns related to potential sampling bias, in that the older participants may represent a group of "supernormals" who can stay healthy and participate in research even at an advanced age. While a few other studies have been conducted in a longitudinal fashion, the follow-up duration was relatively short compared to the lifespan (21-23), which may hamper their ability to estimate changes over longer periods of time.

In preclinical studies, mouse has been a popular species due to its genetic pliability to develop mutant strains and availability for surgery to build disease models (24). In particular, its proximity of genome and physiology to human and short lifespan ( $1 \sim 3$ years) make it an excellent candidate for aging investigations $(25,26)$. Therefore, a longitudinal study on age-related changes in brain physiological parameters of mice will shed new light on neurobiological alterations in aging.

Brain relies on aerobic metabolism to provide energy for neuronal activities (27), thus the oxygen consumption constitutes an interesting parameter to understand the neurobiology of the aging brain. In this study, we examined longitudinal changes in physiological parameters of oxygen supply (i.e., cerebral blood flow, $C B F$ ), venous oxygenation $\left(\mathrm{Y}_{\mathrm{V}}\right)$, and oxygen consumption (i.e., cerebral metabolic rate of oxygen, $\mathrm{CMRO}_{2}$ ). These physiological parameters were evaluated with quantitative MRI techniques in C57BL/6 mice from 3 to 20 months old at an approximately 1-month interval. To allow the mice to survive the large number of imaging sessions, no MRI contrast agents were used and all measures were based on non-contrast-agent MRI sequences. In addition to the physiological measures, $\mathrm{T}_{2}$-weighted images were also collected for the assessment of potential white-matter hyperintensities, which are thought to be associated with insufficient blood supply (28).

\section{MATERIALS AND METHODS}

\section{General}

The experimental protocols involved in this study were approved by the Johns Hopkins Medical Institution Animal Care and Use Committee, and conducted in accordance with the National Institutes of Health guidelines for the care and use of laboratory animals. Five C57BL/6 mice (female, Charles River Laboratories) were scanned longitudinally from 3 to 20 months old at an interval of 1 month. Two of the monthly scans were not completed due to the unavailability of scanner caused by technical problems. Thus, 16 time points $(3 \sim 9,11 \sim 14$, and 16 20 months old) were collected.

One mouse was euthanized after the 16-month-old time point for ethical reasons due to the animal's suffering from a rectal prolapse. Behavioral test using a Y-maze was performed in the remaining mice at $\sim 20$ months of age (i.e., the last time point) to investigate the spatial memory as a representative for cognition status at this advanced age. A spontaneous-alternatingperformance score in percent was obtained from the test (29).

\section{MRI}

All MRI experiments were performed on an 11.7T Bruker Biospec system (Bruker, Ettlingen, Germany) equipped with a horizontal bore and actively shielded pulsed field gradients (maximum intensity of $0.74 \mathrm{~T} / \mathrm{m}$ ). Images were acquired using a 72-mm quadrature volume resonator as a transmitter and a fourelement $(2 \times 2)$ phased-array coil as a receiver. The $\mathrm{B}_{0}$ field over the mouse brain was homogenized by a global shimming (up to 2nd order) based on a pre-acquired subject-specific field map.

Respiration rate was monitored during the experiment to ensure the survival of the mouse. Anesthesia was administered under following regimen: $1.5 \%$ vaporized isoflurane was used for $15 \mathrm{~min}$ as the induction followed by a continuous $1.0 \%$ isoflurane for maintenance until the end of experiments; during the experiment, the maintenance dosage would be increased slightly to $\sim 1.2 \%$ in case that a mouse breathed at a rate $>150$ breaths per minute. At the 10th minute under 1.5\% isoflurane inhalation, the mouse was immobilized with a bite bar and ear pins, and placed onto a water-heated animal bed with temperature control before entering the magnet.

Each MRI session consisted of MRI measurements detailed below.

\section{Cerebral Venous Oxygenation $\left(\mathrm{Y}_{\mathrm{v}}\right)$}

$\mathrm{Y}_{\mathrm{V}}$ was assessed non-invasively from the confluence of sagittal sinuses with a $\mathrm{T}_{2}$-relaxation-under-spin-tagging (TRUST) technique, which was originally developed on human scanners and recently optimized for animal MRI systems (30-32). In order to visualize the confluence of sagittal sinuses, an axial time-of-flight (TOF) sequence was first performed with the following parameters: TR/TE $=20 / 2.6 \mathrm{~ms}$, field of view (FOV) $=16 \times 16 \mathrm{~mm}$, matrix size $=256 \times 256,35$ axial slices, slice thickness $=0.5 \mathrm{~mm}$, and scan duration $=2.2 \mathrm{~min}$. The TRUST scan was then positioned based on the TOF images (31), and was repeated three times to improve precision. The TRUST sequence 
used the following parameters: $\mathrm{TR} / \mathrm{TE}=3500 / 6.5 \mathrm{~ms}, \mathrm{FOV}=16$ $\times 16 \mathrm{~mm}$, matrix size $=128 \times 128$, slice thickness $=0.5 \mathrm{~mm}$, EPI factor $=16$, inversion-slab thickness $=2.5 \mathrm{~mm}$, post-labeling delay $=1000 \mathrm{~ms}$, eTE $=0.25,20,40 \mathrm{~ms}$, echo spacing of $\mathrm{eTE}=$ $5.0 \mathrm{~ms}$, and scan duration $=2.8 \mathrm{~min}$.

Data processing of TRUST MRI was conducted with a customwritten graphic-user-interface (GUI) tool built on MATLAB (MathWorks, Natick, MA) and followed procedures detailed previously $(30,31)$. Briefly, for each TRUST dataset, subtraction between the control and labeled images was performed to obtain difference images (Figure 1A). A region of interest (ROI) was manually drawn on the difference image to encompass the sinus confluence. Four voxels within the ROI with the largest difference signals were selected for spatial averaging. Then, venous blood signal intensities at three different eTEs were fitted into a monoexponential function to obtain $\mathrm{T}_{2}$ (Figure 1A). Finally, $\mathrm{T}_{2}$ was converted into $\mathrm{Y}_{\mathrm{v}}$ using a $\mathrm{T}_{2}-\mathrm{Y}_{\mathrm{v}}$ calibration plot (Figure 1A) reported by Li et al. (33).

\section{Cerebral Blood Flow (CBF)}

Global CBF was evaluated with phase-contrast (PC) MRI covering four major feeding arteries (Figure 1B), i.e., left internal carotid artery (LICA), right internal carotid artery (RICA), left vertebral artery (LVA), and right vertebral artery (RVA), in separate scans to collect corresponding through-plane velocity maps (Figure 1B) $(34,35)$. Prior to the PC scans, we first performed a coronal TOF angiogram ( 7 slices, slice thickness $=$ $0.5 \mathrm{~mm}$, no inter-slice gap, TR/TE $=45 / 2.6 \mathrm{~ms}$, scan duration $=2 \mathrm{~min}$ ) to visualize the feeding arteries. Then, a sagittal TOF (single slice, tilted to contain the target artery identified from coronal TOF images, thickness $=0.5 \mathrm{~mm}$, TR/TE $=$ $60 / 2.5 \mathrm{~ms}$, scan duration $=0.4 \mathrm{~min}$ ) was applied to visualize the in-plane trajectory of the target artery. PC MRI was then positioned using both TOFs and performed using following parameters: TR/TE $=60 / 3.2 \mathrm{~ms}, \mathrm{FOV}=15 \times 15 \mathrm{~mm}$, matrix size $=300 \times 300$, slice thickness $=0.5 \mathrm{~mm}$, number of average $=4$, dummy scan $=8$, receiver bandwidth $=100 \mathrm{kHz}$, flip angle $=25^{\circ}$, partial Fourier acquisition factor $=0.7$, and scan duration $=2.4 \mathrm{~min}$.

Processing of PC dataset was performed with custom-written MATLAB scripts (MathWorks, Natick, MA). The artery of interest was first manually delineated on the complex-difference image (Figure 1B), which shows an excellent contrast between vessel and surrounding tissue. The mask was then applied to the phase velocity map and the integration of arterial voxels yields blood flow through that targeted artery in $\mathrm{ml} / \mathrm{min}$. Summation of blood-flow values across the four major feeding arteries yields total blood flow to the brain. To further account for the brain-size differences and to obtain unit-mass CBF values, the total blood flow was divided by the brain weight, which was calculated as the product of brain volume and density $[1.04 \mathrm{~g} / \mathrm{ml}(36)]$. The global CBF value is written in the unit of milliliters per $100 \mathrm{~g}$ brain tissue per minute $(\mathrm{ml} / 100$ $\mathrm{g} / \mathrm{min}$ ). Inter-rater reproducibility of PC MRI processing has previously been assessed and reported an interrater correlation of $>95 \%$ (34).

\section{Cerebral Metabolic Rate of Oxygen $\left(\mathrm{CMRO}_{2}\right)$}

$\mathrm{CMRO}_{2}$ was computed from $\mathrm{Y}_{\mathrm{v}}$ and $\mathrm{CBF}$ using the Fick principle (37-39), i.e., $\mathrm{CMRO}_{2}=C_{a} \cdot\left(Y_{a}-Y_{v}\right) \cdot C B F$, where $\mathrm{C}_{\mathrm{a}}$ denotes the molar concentration of oxygen in a unit volume of blood and was assumed to be $882.1 \mu \mathrm{mol} \mathrm{O}_{2} / 100 \mathrm{ml}$ blood based on previous literature $(40,41) . \mathrm{Y}_{\mathrm{a}}$ represents arterial oxygen saturation fraction. $\mathrm{Y}_{\mathrm{a}}$ is generally close to unity, and is assumed to be 0.99 in this study (42). $\mathrm{CMRO}_{2}$ is written in the unit of $\mu \mathrm{mol}$ oxygen per $100 \mathrm{~g}$ brain tissue per $\min (\mu \mathrm{mol} \mathrm{O} / 100 \mathrm{~g} / \mathrm{min})$.

\section{Additional Anatomical MRI Sequence}

$\mathrm{A} \mathrm{T}_{2}$-weighted fast spin-echo MRI protocol was utilized to collect anatomical MRI images. The imaging parameters were: TR/TE $=4000 / 26 \mathrm{~ms}, \mathrm{FOV}=15 \times 15 \mathrm{~mm}$, matrix size $=128 \times 128$, slice thickness $=0.5 \mathrm{~mm}$ (without inter-slice gap), echo spacing $=5 \mathrm{~ms}$ (8 spin echoes per scan), 35 axial slices, and scan duration $=1.1 \min (43,44)$.

In humans, microvascular insults to the brain are often assessed by white matter hyperintensities (WMH) on $\mathrm{T}_{2}$ weighted images (45-47). We therefore visually inspected the $\mathrm{T}_{2}$-weighted images to examine the potential presence of hyperintensities. Z.W. (>5 years of experience) and J. X. (>10 years of experience) performed independent image assessments and reached a consensus.

Additionally, the T2-weighted images were analyzed manually by delineating the brain boundary on a slice-by-slice basis (by Z.W.) while referencing to a mouse brain atlas (https://atlas. brain-map.org/). Voxels inside the masks were summed to yield the total brain volume in $\mathrm{mm}^{3}$. The total brain volume was used in the estimation of unit-mass $\mathrm{CBF}$ as described above.

\section{Heart Rate Measurement}

It is known that heart rate is inversely related to the dosage of isoflurane anesthesia in rodents (48). We therefore utilized a MRI sequence to perform in-scanner measurement of heart rate during each session. The sequence acquired the center $k$-space repeatedly at an interval of $8.0 \mathrm{~ms}$, thereby yielding a time course of MR signal intensity, the period of which is the R-R interval (49). Two measurements were performed in each session and the values were averaged. This allowed us to examine whether there is an age-dependent change in anesthesia level and how this may affect the interpretation of the physiological data.

\section{Statistical Analyses}

All statistical analyses were performed with SPSS v23 (IBM Corporation, Armonk, NY). A linear mixed-effect model was utilized to analyze longitudinal measurements (i.e., $\mathrm{Y}_{\mathrm{V}}, \mathrm{CBF}$, $\mathrm{CMRO}_{2}$, and heart rate), in which age was a fixed effect and individual mouse was a random effect. An age ${ }^{2}$ term was also tested in the model to determine any non-linear effect of age. A $p$-value $<0.05$ was considered significant.

\section{RESULTS}

Figure 1A shows representative data from TRUST MRI, which consisted of control, labeled, and difference images acquired 

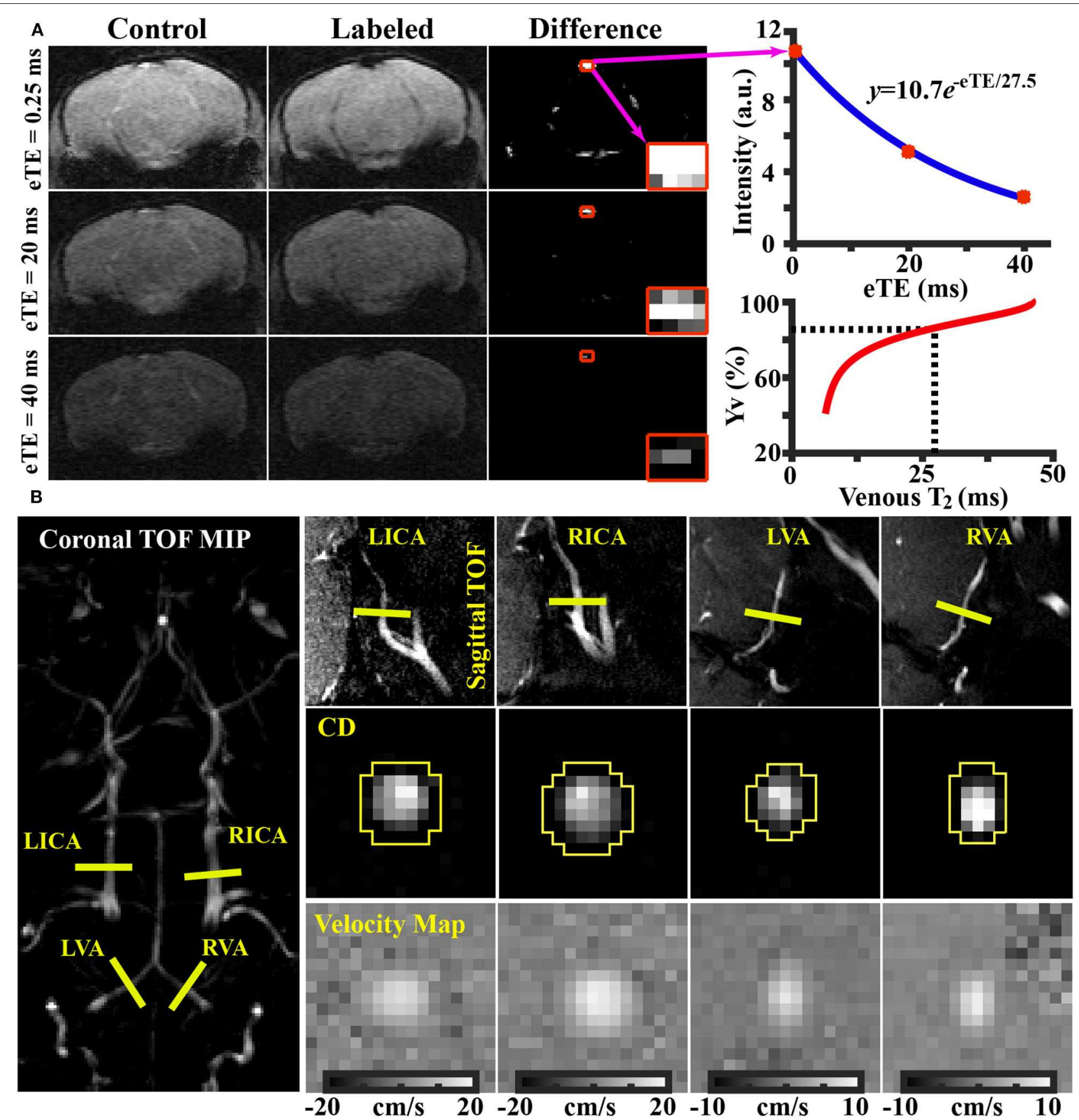

FIGURE 1 | Representative results of (A) TRUST and (B) PC MRI. (A) Left panel: control, labeled, and difference images from TRUST MRI obtained at different effective TE (eTE) values. The sinus confluence is shown in red squares. Right upper panel: Blood signal in the sinus confluence as a function of eTE. Blue curve indicates fitting results. Right lower panel: $Y_{\mathrm{v}}-\mathrm{T}_{2}$ calibration plot used to convert blood $T_{2}$ to oxygenation (33). (B) Left panel: imaging slice locations of PC MRI overlaid on a TOF image. Right upper panel: PC MRI imaging locations overlaid on respective sagittal TOF image. Right middle panel: complex difference (CD) images of the four arteries. Right lower panel: velocity maps of the four arteries.

at different eTE values. Figure 1B illustrates representative PC images. Both complex difference (CD) and velocity map images are shown. ROIs (yellow polygons in Figure 1B) delineating the target vessels are also displayed.

The longitudinal time course for $\mathrm{Y}_{\mathrm{V}}$ is shown in Figure 2A. There was an age-related decrease in $Y_{\mathrm{v}}(p=0.002)$ from 3 to
20 months of age. Furthermore, the quadratic term of age was also significant $(p=0.013)$, suggesting that the age-dependence of $\mathrm{Y}_{\mathrm{v}}$ was non-linear $\left(\mathrm{Y}_{v}=0.028\right.$ Age $^{2}-0.840$ Age +88.743$)$. Figure 2B displays the longitudinal time courses of $\mathrm{CBF}$, which exhibited an increase with age $(p=0.017)(C B F=1.93$ Age + $200.62 \mathrm{ml} / 100 \mathrm{~g} / \mathrm{min})$. There was not a quadratic effect of age on 


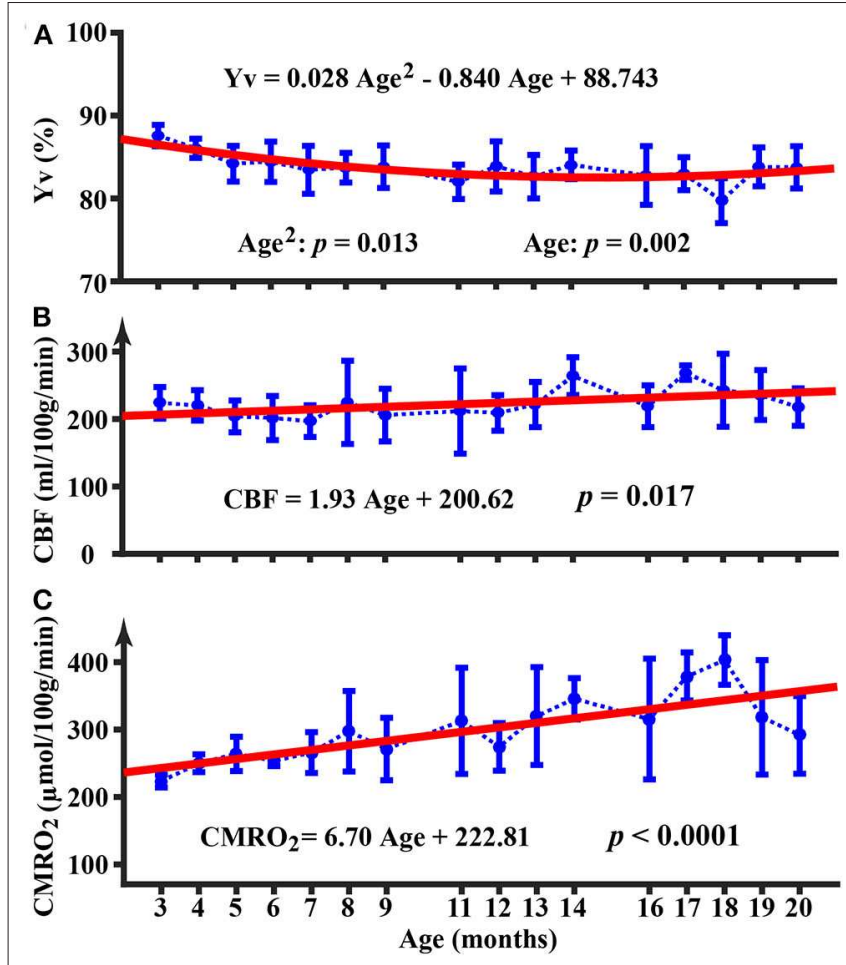

FIGURE 2 | Longitudinal time courses of physiological parameters of $Y_{V}(\mathbf{A})$, $\mathrm{CBF}(\mathbf{B})$, and $\mathrm{CMRO}_{2}(\mathbf{C})$. Error bar denotes the standard deviation across mice $(N=5)$. Red line indicates the fitting curve from a mixed-effect model. Equation shows the fixed term estimated from the mixed-effect model.

CBF measure $(p=0.64)$. Longitudinal time course of $\mathrm{CMRO}_{2}$ is shown in Figure $2 \mathrm{C}$ and exhibited an increase with age $(p<$ $0.0001)\left(\mathrm{CMRO}_{2}=6.70\right.$ Age $\left.+222.81 \mu \mathrm{mol} / 100 \mathrm{~g} / \mathrm{min}\right)$. The $\mathrm{Age}^{2}$ term was not significant for $\mathrm{CMRO}_{2}(p=0.12)$. At 19 and 20 months of age, there appeared to be a decrease in $\mathrm{CMRO}_{2}$; but these values were not significantly different from $\mathrm{CMRO}_{2}$ at 18 months of age ( $p=0.11$ and 0.09 , respectively).

Figure 3 shows the longitudinal time course of heart rate. It can be seen that the heart rate is within the range of 300 400 beats per minute (bpm), which is consistent with those reported in the literature under similar anesthetic conditions (50). There was no significant change in heart rate with age $(p=0.47)$.

The Y-maze test revealed an average spontaneous-alternatingperformance score of $62 \pm 20 \%$. These scores are within the normal range of wild-type mice $(29,51)$, indicating that the utilized mice did not exhibit obvious cognitive decline throughout the study period.

Visual inspection of $\mathrm{T}_{2}$-weighted images revealed no $\mathrm{WMH}$ in the brain, even at 20 months of age (Figure 4).

\section{DISCUSSION}

To the best of our knowledge, the present work is the first longitudinal study to characterize brain energy homeostasis across the adult lifespan of mice. Our findings suggested that brain perfusion and oxygen metabolic rate both increased within

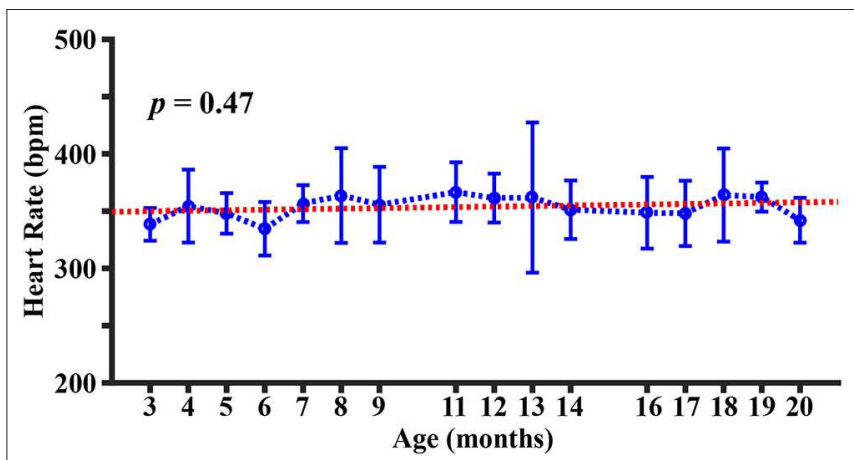

FIGURE 3 | Longitudinal time course of heart rate. Error bar denotes the standard deviation across mice $(N=5)$. Red line indicates the fitting curve from a mixed-effect model.

the age range of 3 to 20 months in C57BL/6 mice, consistent with the notion of flow-metabolism coupling (52). On the other hand, systemic parameters such as heart rate did not show a significant change with age. Results from the present study also provide normative data on these important brain physiological parameters of $\mathrm{C} 57 \mathrm{BL} / 6$ mice, which is the most widely-used mouse strain for developing disease models $(53,54)$.

Our data suggested that $\mathrm{CMRO}_{2}$, an index of the brain's energy budget and a surrogate marker of aggregated brain cell activity, is in the range of $250-350 \mu \mathrm{mol} / 100 \mathrm{~g} / \mathrm{min}$ in mice. These values are in good agreement with reports in the literature using ${ }^{17} \mathrm{O}$ magnetic resonance spectroscopy $(55,56)$ or Doppler/spectroscopic OCT methods (40), and are higher than human $\mathrm{CMRO}_{2}$ values of $120-200 \mu \mathrm{mol} / \mathrm{min} / 100 \mathrm{~g}$, showing consistency with reports that mouse brain consumes more energy (per unit volume tissue) compared to humans $(57,58)$. Our longitudinal data also confirmed previous cross-sectional observations in humans that $\mathrm{CMRO}_{2}$ does in fact increase with age $(10,17)$. In terms of the reason for age-related increase in oxygen metabolism, it could be a compensatory response to reduced efficiency in neural computation and/or cellular machinery of oxidative metabolism and energy production chain. It has been reported that 24 month-old rats reveal $\geq 30 \%$ (59) synapse losses in comparison with 3 -month-old young controls. Therefore, it is plausible that escalated neural computation is needed in the presence of synaptic loss.

Quantification of CBF in mice is not trivial. The present study revealed, for the first time, that unit-volume $\mathrm{CBF}$ increases with age in mice. Compared to the literature, our CBF values of 200$250 \mathrm{ml} / 100 \mathrm{~g} / \mathrm{min}$ in mice are in good agreement with those obtained with arterial-spin-labeling (ASL) MRI, which showed values of $\sim 200 \mathrm{ml} / \mathrm{min} / 100 \mathrm{~g}$ for mice at 3 months of age $(60,61)$. However, previous ASL studies in mice have generally failed to observe an age effect on CBF. For example, Maier et al. performed a longitudinal ASL study $(1.5,2.5,5,7,13$, and 18 months old) in mice and found that $\mathrm{CBF}$ was constant across age (62). Similarly, Hirschler et al. reported in a cross-sectional ASL study that no CBF difference was observed between mice 6 and 26 months of age (63). Note that the ASL technique relies on the spin tagging principle to generate perfusion information 

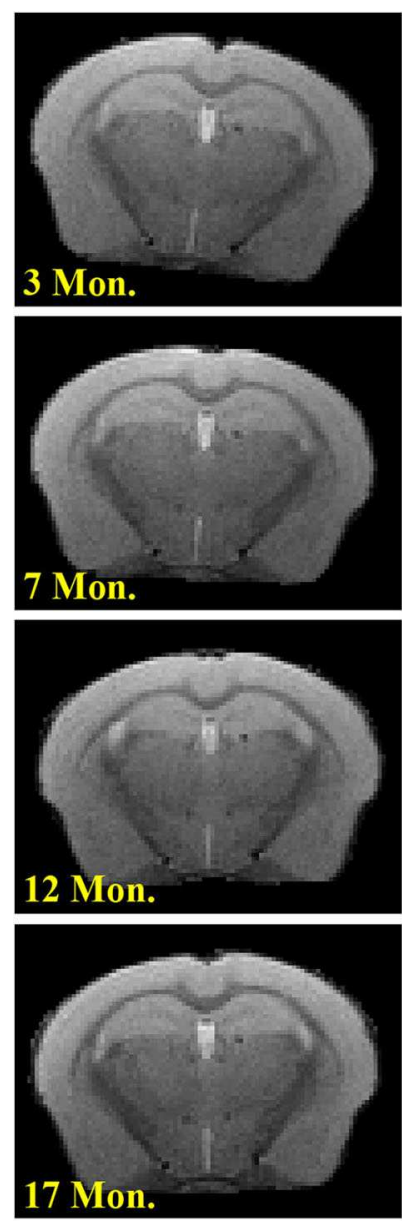
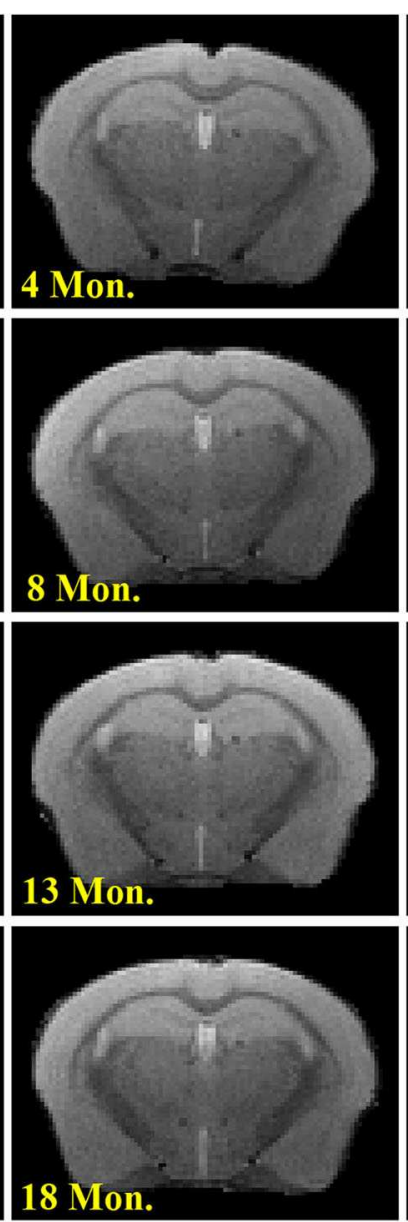
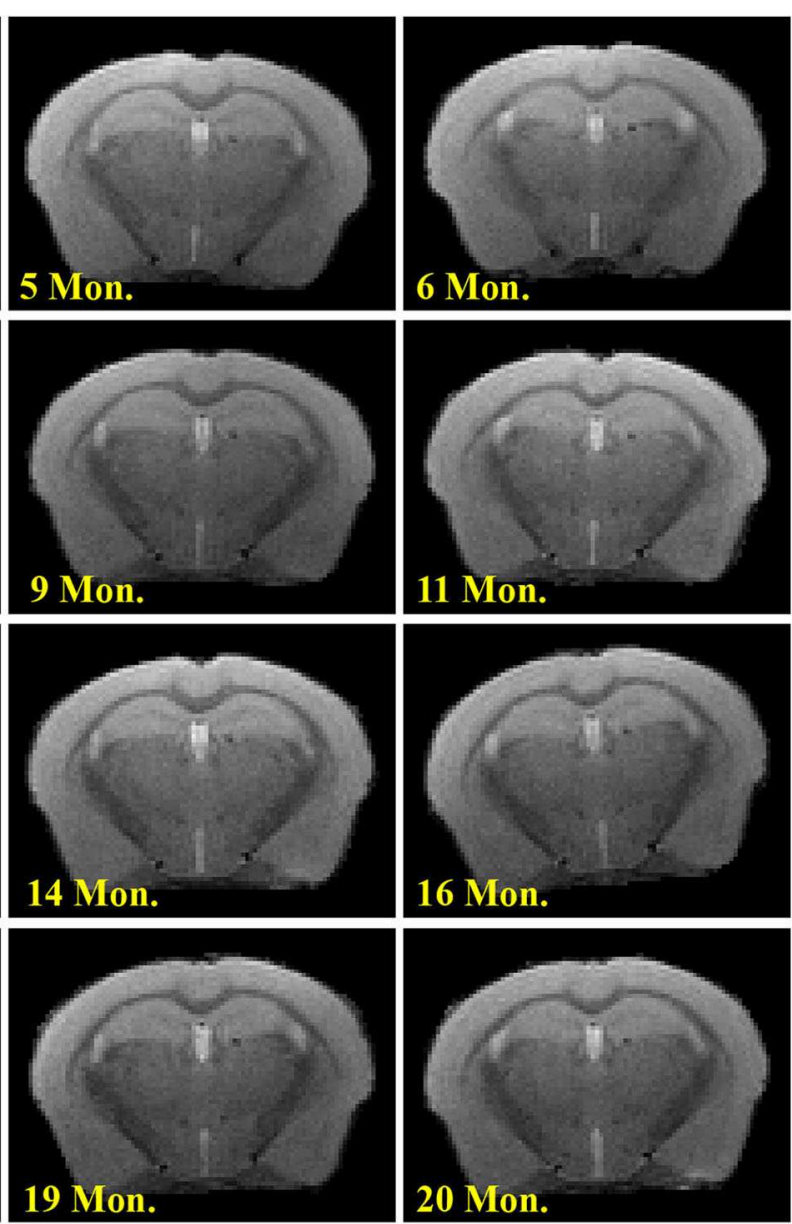

FIGURE 4 | Longitudinal $T_{2}$-weighted images in a representative mouse.

after pair-wise subtraction (64). A limitation of ASL MRI is that the SNR of this signal is relatively low, thus it is typically used in a lower resolution setting in humans. In the mouse brain, spatial resolution has to be increased for delineation of structures, which results in a further decrease in SNR in mouse ASL data. In addition, ASL MRI also suffers from multiple confounding factors, e.g., bolus arrival time, labelling efficiency, and vessel contributions, in terms of its quantification. On the other hand, PC MRI utilizes the principle that flowing spins can accumulate a phase proportional to its velocity through the use of a pair of bipolar gradients (65). Two separate scans with inverted gradient polarities can be performed to cancel phases due to spurious field inhomogeneities and thereby allows the calculation of a flow map. The quantification of blood flow in PC is more straightforward with fewer confounding factors. Moreover, the coefficient of variation (CoV) of PC (5.3\%) (34) was found to be smaller than that in ASL $(\sim 10 \%)$ (66), suggesting that PC is more reproducible. Therefore, the present study used the PC MRI technique to quantify global CBF, and the sequence has been extensively characterized previously for quantitative flow measurement $(34,67)$. CBF measurement using PC MRI presents a new approach for hemodynamic assessment in mice.
In humans, it has been suggested that $\mathrm{CBF}$ decreases with age $(10,68,69)$. This decrease is thought to be attributed to increased arterial stiffness, thickening of basement membrane, stenosis or narrowing of vessel lumen, and development of arteriolosclerosis $(70,71)$. The present observation of an age increase in $\mathrm{CBF}$ of mice is apparently different from the human findings. One possible explanation is species differences. Humans have a much longer lifespan and thus vascular degradation may be substantial in older individuals. In contrast, it is possible that cerebral vessels are still in good health in aged mice. This is consistent with the histology study where cerebral capillary density was not significantly different between 24-month-old and 7-month-old C57BL/6 mice (72), and the notion that aged mice rarely have strokes (73) or WMH as shown in the present study. Therefore, when brain metabolic rate increases with age, mouse brain is able to garner more blood flow to meet its demand, following the flow-metabolism coupling principle (52). It is also interesting to compare $\mathrm{CBF}$ time-pattern in mice to that in humans for the same absolute time period. Previous studies that investigated CBF changes in neonates and young children have shown that, the first few months of humans, CBF exhibited an increase from $\sim 20$ $\mathrm{ml} / 100 \mathrm{~g} / \mathrm{min}$ to $\sim 70 \mathrm{ml} / 100 \mathrm{~g} / \mathrm{min}$ from 30 to 120 gestational 
weeks (i.e., 7 to 28 months) (74). Thus, it is plausible that CBF can increase in the first two years of life, and this occurs in both humans and mice.

One potential confounding factor in animal studies like ours is the anesthetic effect on physiological parameters. In this study, the anesthetic regimen used was the same throughout the study period. To further confirm that the age changes observed in this work were not attributed to variations in anesthetic level, we measured heart rate as an index of anesthetic depth. As shown in Figure 3, the heart rate did not reveal a dependence on age, indicating that the anesthetic level was not a contributor to the physiological alternations observed in the present study. This is consistent with literature that resting heart rate does not change with age (75). Isoflurane is known to induce an increase in $\mathrm{CBF}$ and a decrease in $\mathrm{CMRO}_{2}$ (76). Therefore, absolute values of metabolic parameters during awake state may be different from those reported here. Based on the relationship among CBF, CMRO2, and OEF, Yv measured under isoflurane is expected to be greater than that under awake state. Additionally, it should be pointed out that different anesthetic agents may induce different physiological alterations. For example, dexmedetomidine has been reported to be associated with decreases in both CBF and $\mathrm{CMRO}_{2}(77)$. Therefore, absolute values of physiological parameters under different anesthesia are not directly comparable; however, the age pattern is expected to be valid when a consistent anesthetic scheme is used.

Human studies have reported that $\mathrm{Y}_{\mathrm{a}}$ is minimally affected by age with a $1 \sim 2 \%$ decrease across the lifespan (10). On the other hand, noninvasive measurement of $\mathrm{Y}_{\mathrm{a}}$ in mouse is not trivial, and the measurement error could easily exceed the systematic error in $\mathrm{Y}_{\mathrm{a}}$. Regarding $\mathrm{C}_{\mathrm{a}}$, it is related to the hemoglobin level, which is not significantly different between young and older age according to the literature (78). Therefore, the assumptions on $\mathrm{Y}_{\mathrm{a}}$ and $\mathrm{C}_{\mathrm{a}}$ are not expected to alter the major conclusions in the current study.

Findings in current study should be interpreted in the context of several limitations. First, brain perfusion and oxygen consumption were measured in a global manner without spatial information. Regional maps can further enhance our understanding of spatial distributions of oxygen metabolism across the brain. Second, arterial oxygenation was based on an assumed value (99\%) instead of subject-specific measurements, e.g., with pulse oximeter. The $\mathrm{CMRO}_{2}$ estimation is thus based upon such assumptions. However, we should point out that our study used a longitudinal design thus inter-subject variations in $\mathrm{Y}_{\mathrm{a}}$ should not affect our conclusion. Finally, this study has only used female C57BL/6 mice. Thus potential sex effects on our findings require further studies. The number of mice used in this study was relatively small. However, we would like to point out

\section{REFERENCES}

1. Mattay VS, Goldberg TE, Sambataro F, Weinberger DR. Neurobiology of cognitive aging: insights from imaging genetics. Biol Psychol. (2008) 79:922. doi: 10.1016/j.biopsycho.2008.03.015 that, when it comes to study power, one should also consider the number of data points from each mouse. In the present study, each mouse underwent 16 sessions (one with 12 sessions). Thus the total number of experimental sessions was 76 , which is considered large compared to many studies in the literature. As a result, the statistical power of our findings was satisfactory, with a $p$-value of 0.002 for $\mathrm{Y}_{\mathrm{v}}$ and $<0.0001$ for $\mathrm{CMRO}_{2}$. In addition, there are limitations of using animal models to study human conditions. In this case, the aging process in humans is expected to be different from that in mice in many aspects (79-81). Aged mice often do not develop neurodegeneration and have low prevalence of cardiovascular disease, possibly due to species differences in physiology, disparity in maximal lifespan, diet, and environmental factors. Thus caution should be used when generalizing these observations to other mouse strains.

\section{CONCLUSIONS}

We conducted a longitudinal assessment of brain physiological parameters in $\mathrm{C} 57 \mathrm{BL} / 6$ mice, and observed an age-related increase in brain perfusion and oxygen consumption within 3 to 20 months of age. While the age increases in oxygen metabolic parameters are consistent with findings in humans and suggest a compensatory hypermetabolism of brain tissue, the continuous increase in perfusion suggests that cerebrovascular function remains relatively intact in aged C57BL/6 mice and is consistent with an absence of $\mathrm{WMH}$, in contrast to human elderly individuals.

\section{DATA AVAILABILITY STATEMENT}

The datasets generated for this study are available on request to the corresponding author.

\section{ETHICS STATEMENT}

The animal study was reviewed and approved by Johns Hopkins Medical Institution Animal Care and Use Committee.

\section{AUTHOR CONTRIBUTIONS}

ZW and HL designed the study. ZW, LC, and JX performed the experiments and collected the data. XH helped with the statistical analyses. PZ and HL helped with the data interpretation. ZW and HL wrote the manuscript with editing from all other authors.

\section{FUNDING}

This work was supported by the Grant Sponsors: NIH R01 MH084021, NIH R21 AG058413, and NIH P41 EB015909.

2. Wyss-Coray T. Ageing, neurodegeneration and brain rejuvenation. Nature (2016) 539:180-6. doi: 10.1038/nature20411

3. Irwin K, Sexton C, Daniel T, Lawlor B, Naci L. Healthy aging and dementia: two roads diverging in midlife? Front Aging Neurosci. (2018) 10:275. doi: 10.3389/fnagi.2018.00275 
4. Fletcher MA, Low KA, Boyd R, Zimmerman B, Gordon BA, Tan CH, et al. Comparing aging and fitness effects on brain anatomy. Front Hum Neurosci. (2016) 10:286. doi: 10.3389/fnhum.2016.00286

5. Smith CD, Chebrolu H, Wekstein DR, Schmitt FA, Markesbery WR. Age and gender effects on human brain anatomy: a voxel-based morphometric study in healthy elderly. Neurobiol Aging. (2007) 28:1075-87. doi: 10.1016/j.neurobiolaging.2006.05.018

6. Fjell AM, Walhovd KB. Structural brain changes in aging: courses, causes and cognitive consequences. Rev Neurosci. (2010) 21:187-221. doi: 10.1515/revneuro.2010.21.3.187

7. Gu T, Fu C, Shen Z, Guo H, Zou M, Chen M, et al. Age-Related wholeBrain structural changes in relation to cardiovascular risks across the adult age spectrum. Front Aging Neurosci. (2019) 11:85. doi: 10.3389/fnagi.2019.00085

8. Guo H, Siu W, D'Arcy RC, Black SE, Grajauskas LA, Singh S, et al. MRI assessment of whole-brain structural changes in aging. Clin Interv Aging. (2017) 12:1251-70. doi: 10.2147/CIA.S139515

9. Tomasi D, Volkow ND. Aging and functional brain networks. Mol Psychiatry. (2012) 17:471:549-58. doi: 10.1038/mp.2011.81

10. Lu H, Xu F, Rodrigue KM, Kennedy KM, Cheng Y, Flicker B, et al. Alterations in cerebral metabolic rate and blood supply across the adult lifespan. Cereb Cortex. (2011) 21:1426-634. doi: 10.1093/cercor/bhq224

11. Liang $Z$, Liu $X$, Zhang $N$. Dynamic resting state functional connectivity in awake and anesthetized rodents. Neuroimage. (2015) 104:89-99. doi: 10.1016/j.neuroimage.2014.10.013

12. Liu X, Duyn JH. Time-varying functional network information extracted from brief instances of spontaneous brain activity. Proc Natl Acad Sci USA. (2013) 110:4392-7. doi: 10.1073/pnas.1216856110

13. Li HJ, Hou XH, Liu HH, Yue CL, Lu GM, Zuo XN. Putting age-related task activation into large-scale brain networks: a meta-analysis of 114 fMRI studies on healthy aging. Neurosci Biobehav Rev. (2015) 57:15674. doi: 10.1016/j.neubiorev.2015.08.013

14. Sala-Llonch R, Bartres-Faz D, Junque C. Reorganization of brain networks in aging: a review of functional connectivity studies. Front Psychol. (2015) 6:663. doi: 10.3389/fpsyg.2015.00663

15. Park DC, Reuter-Lorenz P. The adaptive brain: aging and neurocognitive scaffolding. Annu Rev Psychol. (2009) 60:17396. doi: 10.1146/annurev.psych.59.103006.093656

16. Turner GR, Spreng RN. Executive functions and neurocognitive aging: dissociable patterns of brain activity. Neurobiol Aging. (2012) 33:826 e113. doi: 10.1016/j.neurobiolaging.2011.06.005

17. Peng SL, Dumas JA, Park DC, Liu P, Filbey FM, McAdams CJ, et al. Agerelated increase of resting metabolic rate in the human brain. Neuroimage. (2014) 98:176-83. doi: 10.1016/j.neuroimage.2014.04.078

18. Cabeza R. Hemispheric asymmetry reduction in older adults: the hAROLD model. Psychology and Aging. (2002) 17:85100. doi: 10.1037/0882-7974.17.1.85

19. Ferando I, Faas GC, Mody I. Diminished kCC2 confounds synapse specificity of ITP during senescence. Nat Neurosci. (2016) 19:1197200. doi: 10.1038/nn.4357

20. Samson RD, Barnes CA. Impact of aging brain circuits on cognition. Eur J Neurosci. (2013) 37:1903-15. doi: 10.1111/ejn.12183

21. Liu W, Wei D, Chen Q, Yang W, Meng J, Wu G, et al. Longitudinal test-retest neuroimaging data from healthy young adults in southwest china. Sci Data. (2017) 4:170017. doi: 10.1038/sdata.2017.17

22. De Vis JB, Peng SL, Chen X, Li Y, Liu P, Sur S, et al. Arterialspin-labeling (ASL) perfusion $\mathrm{mRI}$ predicts cognitive function in elderly individuals: a 4-year longitudinal study. J Magn Reson Imaging. (2018) 48:44958. doi: 10.1002/jmri.25938

23. Vetter NC, Steding J, Jurk S, Ripke S, Mennigen E, Smolka MN. Reliability in adolescent fMRI within two years - a comparison of three tasks. Sci Rep. (2017) 7:2287. doi: 10.1038/s41598-017-02334-7

24. Vandamme TF. Use of rodents as models of human diseases. J Pharm Bioallied Sci. (2014) 6:2-9. doi: 10.4103/0975-7406.124301

25. Yue F, Cheng Y, Breschi A, Vierstra J, Wu W, Ryba T, et al. A comparative encyclopedia of dNA elements in the mouse genome. Nature. (2014) 515:35564. doi: 10.1038/nature13992

26. Dutta S, Sengupta P. Men and mice: relating their ages. Life Sci. (2016) 152:244-8. doi: 10.1016/j.lfs.2015.10.025
27. Magistretti PJ, Allaman I. A cellular perspective on brain energy metabolism and functional imaging. Neuron. (2015) 86:883-901. doi: 10.1016/j.neuron.2015.03.035

28. Pantoni L. Cerebral small vessel disease: from pathogenesis and clinical characteristics to therapeutic challenges. Lancet Neurol. (2010) 9:689701. doi: 10.1016/s1474-4422(10)70104-6

29. Liu N, Wang Y, An AY, Banker C, Qian YH, O’Donnell JM. Single housinginduced effects on cognitive impairment and depression-like behavior in male and female mice involve neuroplasticity-related signaling. Eur J Neurosci. (2019) doi: 10.1111/ejn.14565

30. $\mathrm{Lu} \mathrm{H}, \mathrm{Ge} Y$. Quantitative evaluation of oxygenation in venous vessels using t2-Relaxation-Under-Spin-Tagging mRI. Magn Reson Med. (2008) 60:35763. doi: $10.1002 / \mathrm{mrm} .21627$

31. Wei Z, Xu J, Liu P, Chen L, Li W, van Zijl P, et al. Quantitative assessment of cerebral venous blood $\mathrm{t} 2$ in mouse at 11.7T: implementation, optimization, and age effect. Magn Reson Med. (2018) 80:521-8. doi: 10.1002/mrm.27046

32. Watchmaker JM, Juttukonda MR, Davis LT, Scott AO, Faraco CC, Gindville $\mathrm{MC}$, et al. Hemodynamic mechanisms underlying elevated oxygen extraction fraction (OEF) in moyamoya and sickle cell anemia patients. J Cereb Blood Flow Metab. (2018) 38:1618-30. doi: 10.1177/0271678X16682509

33. Li W, van Zijl PCM. Quantitative theory for the transverse relaxation time of blood water. NMR Biomed. (2020) 2020:e4207. doi: 10.1002/nbm.4207

34. Wei Z, Chen L, Lin Z, Jiang D, Xu J, Liu P, et al. Optimization of phase-contrast mRI for the estimation of global cerebral blood flow of mice at 11.7T. Magn Reson Med. (2019) 81:2566-75. doi: 10.1002/mrm.27592

35. Zheng G, Wen J, Yu W, Li X, Zhang Z, Chen H, et al. Anemia rather than hypertension contributes to cerebral hyperperfusion in young adults undergoing hemodialysis: a phase contrast mRI study. Sci Rep. (2016) 6:22346. doi: 10.1038/srep22346

36. Bothe HW, Bodsch W, Hossmann KA. Relationship between specific gravity, water content, and serum protein extravasation in various types of vasogenic brain edema. Acta Neuropathol. (1984) 64:37-42. doi: 10.1007/bf00695604

37. Kety SS, Schmidt CF. The effects of altered arterial tensions of carbon dioxide and oxygen on cerebral blood flow and cerebral oxygen consumption of normal young men. J Clin Invest. (1948) 27:484-92. doi: 10.1172/jci101995

38. Bulte DP, Kelly M, Germuska M, Xie J, Chappell MA, Okell TW, et al. Quantitative measurement of cerebral physiology using respiratory-calibrated MRI. Neuroimage. (2012) 60:582-91. doi: 10.1016/j.neuroimage.2011.12.017

39. $\mathrm{Xu} \mathrm{F}, \mathrm{Ge} \mathrm{Y,} \mathrm{Lu} \mathrm{H}$. Noninvasive quantification of whole-brain cerebral metabolic rate of oxygen (CMRO2) by mRI. Magn Reson Med. (2009) 62:1418. doi: 10.1002/mrm.21994

40. Chong SP, Merkle CW, Leahy C, Srinivasan VJ. Cerebral metabolic rate of oxygen (CMRO2) assessed by combined doppler and spectroscopic oCT. Biomed Opt Express. (2015) 6:3941-51. doi: 10.1364/BOE.6.003941

41. Ulatowski JA, Oja JME, Suarez JI, Kauppinen RA, Traystman RJ, van Zijl PCM. In vivo determination of absolute cerebral blood volume using hemoglobin as a natural contrast agent: an mRI study using altered arterial carbon dioxide tension. J Cereb Blood Flow Metab. (1999) 19:80917. doi: 10.1097/00004647-199907000-00012

42. Lin AL, Qin Q, Zhao X, Duong TQ. Blood longitudinal (T1) and transverse (T2) relaxation time constants at 11.7 tesla. MAGMA. (2012) 25:2459. doi: 10.1007/s10334-011-0287-2

43. Nessler S, Boretius S, Stadelmann C, Bittner A, Merkler D, Hartung HP, et al. Early MRI changes in a mouse model of multiple sclerosis are predictive of severe inflammatory tissue damage. Brain. (2007) 130(Pt 8):2186-98. doi: 10.1093/brain/awm105

44. Natt O, Watanabe T, Boretius S, Radulovic J, Frahm J, Michaelis T. Highresolution $3 \mathrm{D} \mathrm{mRI}$ of mouse brain reveals small cerebral structures in vivo. J Neurosci Methods. (2002) 120:203-9. doi: 10.1016/s0165-0270(02)00211-x

45. Atwi S, Metcalfe AWS, Robertson AD, Rezmovitz J, Anderson ND, MacIntosh BJ. Attention-Related brain activation is altered in older adults with white matter hyperintensities using multi-Echo fMRI. Front Neurosci. (2018) 12:748. doi: 10.3389/fnins.2018.00748

46. Wardlaw JM, Valdes Hernandez MC, Munoz-Maniega S. What are white matter hyperintensities made of? Relevance to vascular cognitive impairment. J Am Heart Assoc. (2015) 4:001140. doi: 10.1161/JAHA.114.001140

47. Knight MJ, McCann B, Tsivos D, Dillon S, Coulthard E, Kauppinen RA. Quantitative T2 mapping of white matter: applications for 
ageing and cognitive decline. Phys Med Biol. (2016) 61:5587605. doi: 10.1088/0031-9155/61/15/5587

48. Yang C-F, Yu-Chih Chen M, Chen T-I, Cheng C-F. Dose-dependent effects of isoflurane on cardiovascular function in rats. Tzu Chi Med J. (2014) 26:119-22. doi: 10.1016/j.tcmj.2014.07.005

49. Piekarski E, Chitiboi T, Ramb R, Feng L, Axel L. Use of self-gated radial cardiovascular magnetic resonance to detect and classify arrhythmias (atrial fibrillation and premature ventricular contraction). J Cardiovasc Magn Reson. (2016) 18:83. doi: 10.1186/s12968-016-0306-6

50. Constantinides C, Murphy K. Molecular and integrative physiological effects of isoflurane anesthesia: the paradigm of cardiovascular studies in rodents using magnetic resonance imaging. Front Cardiovasc Med. (2016) 3:23. doi: $10.3389 / \mathrm{fcvm} .2016 .00023$

51. Hakimizadeh E, Jandaghi F, Hajmohammadi M, Fatemi I, Kaeidi A, Shamsizadeh A, et al. Pistachio extract improves neurocognitive behaviors in ovariectomized mice. Res J Pharmacogn. (2019) 6:45-51. doi: 10.22127/rjp.2019.93515

52. Chiarelli PA, Bulte DP, Gallichan D, Piechnik SK, Wise R, Jezzard P. Flowmetabolism coupling in human visual, motor, and supplementary motor areas assessed by magnetic resonance imaging. Magn Reson Med. (2007) 57:538-47. doi: 10.1002/mrm.21171

53. Bryant $\mathrm{CD}$. The blessings and curses of $\mathrm{c} 57 \mathrm{BL} / 6$ substrains in mouse genetic studies. Ann N Y Acad Sci. (2011) 1245:313. doi: $10.1111 / j .1749-6632.2011 .06325 . x$

54. Song HK, Hwang DY. Use of c57BL/6N mice on the variety of immunological researches. Lab Anim Res. (2017) 33:119-23. doi: 10.5625/lar.2017.33.2.119

55. Lou S, Lepak VC, Eberly LE, Roth B, Cui W, Zhu XH, et al. Oxygen consumption deficit in huntington disease mouse brain under metabolic stress. Hum Mol Genet. (2016) 25:2813-26. doi: 10.1093/hmg/ddw138

56. Cui W, Zhu XH, Vollmers ML, Colonna ET, Adriany G, Tramm B, et al. Noninvasive measurement of cerebral oxygen metabolism in the mouse brain by ultra-high field (17)O mR spectroscopy. J Cereb Blood Flow Metab. (2013) 33:1846-9. doi: $10.1038 / \mathrm{jcbfm} .2013 .172$

57. Herculano-Houzel S. Scaling of brain metabolism with a fixed energy budget per neuron: implications for neuronal activity, plasticity and evolution. PLoS ONE. (2011) 6:e17514. doi: 10.1371/journal.pone.0017514

58. Karbowski J. Global and regional brain metabolic scaling and its functional consequences. BMC Biol. (2007) 5:18. doi: 10.1186/1741-7007-5-18

59. Chen S, Hillman DE. Dying-back of purkinje cell dendrites with synapse loss in aging rats. J Neurocytol. (1999) 28:187-96. doi: 10.1023/a:1007015721754

60. Xu J, Qin Q, Wu D, Hua J, Song X, McMahon MT, et al. Steady pulsed imaging and labeling scheme for noninvasive perfusion imaging. Magn Reson Med. (2016) 75:238-48. doi: 10.1002/mrm.25641

61. Duhamel G, Callot V, Tachrount M, Alsop DC, Cozzone PJ. Pseudocontinuous arterial spin labeling at very high magnetic field $(11.75 \mathrm{t})$ for high-resolution mouse brain perfusion imaging. Magn Reson Med. (2012) 67:1225-36. doi: $10.1002 / \mathrm{mrm} .23096$

62. Maier FC, Wehrl HF, Schmid AM, Mannheim JG, Wiehr S, Lerdkrai C, et al. Longitudinal pET-MRI reveals beta-amyloid deposition and $\mathrm{rCBF}$ dynamics and connects vascular amyloidosis to quantitative loss of perfusion. Nat Med. (2014) 20:1485-92. doi: 10.1038/nm.3734

63. Hirschler L, Munting LP, Khmelinskii A, Teeuwisse WM, Suidgeest E, Warnking JM, et al. Transit time mapping in the mouse brain using timeencoded pCASL. NMR Biomed. (2018) 31:3855. doi: 10.1002/nbm.3855

64. Alsop DC, Detre JA, Golay X, Gunther M, Hendrikse J, Hernandez-Garcia L, et al. Recommended implementation of arterial spin-labeled perfusion mRI for clinical applications: a consensus of the iSMRM perfusion study group and the european consortium for aSL in dementia. Magn Reson Med. (2015) 73:102-16. doi: $10.1002 / \mathrm{mrm} .25197$

65. Lotz J, Meier C, Leppert A, Galanski M. Cardiovascular flow measurement with phase-contrast $\mathrm{mR}$ imaging: basic facts and implementation. Radiographics. (2002) 22:65171. doi: 10.1148/radiographics.22.3.g02ma11651

66. Naresh NK, Chen X, Moran E, Tian Y, French BA, Epstein FH. Repeatability and variability of myocardial perfusion imaging techniques in mice: comparison of arterial spin labeling and first-pass contrast-enhanced MRI. Magn Reson Med. (2016) 75:2394-405. doi: 10.1002/mrm.25769

67. Peng SL, Su P, Wang FN, Cao Y, Zhang R, Lu H, et al. Optimization of phasecontrast MRI for the quantification of whole-brain cerebral blood flow. J Magn Reson Imaging. (2015) 42:1126-33. doi: 10.1002/jmri.24866

68. Chen JJ, Rosas HD, Salat DH. Age-associated reductions in cerebral blood flow are independent from regional atrophy. Neuroimage. (2011) 55:46878. doi: 10.1016/j.neuroimage.2010.12.032

69. Catchlove SJ, Macpherson H, Hughes ME, Chen Y, Parrish TB, Pipingas A. An investigation of cerebral oxygen utilization, blood flow and cognition in healthy aging. PLoS ONE. (2018) 13:e0197055. doi: 10.1371/journal.pone.0197055

70. Head T, Daunert S, Goldschmidt-Clermont PJ. The aging risk and atherosclerosis: a Fresh look at arterial homeostasis. Front Genet. (2017) 8:216. doi: $10.3389 /$ fgene.2017.00216

71. Lee HY, Oh BH. Aging and arterial stiffness. Circ J. (2010) 74:225762. doi: 10.1253/circj.cj-10-0910

72. Tucsek Z, Toth P, Tarantini S, Sosnowska D, Gautam T, Warrington JP, et al. Aging exacerbates obesity-induced cerebromicrovascular rarefaction, neurovascular uncoupling, and cognitive decline in mice. J Gerontol A Biol Sci Med Sci. (2014) 69:1339-52. doi: 10.1093/gerona/glu080

73. Snyder JM, Ward JM, Treuting PM. Cause-of-Death analysis in rodent aging studies. Vet Pathol. (2016) 53:233-43. doi: 10.1177/03009858156 10391

74. Liu P, Qi Y, Lin Z, Guo Q, Wang X, Lu H. Assessment of cerebral blood flow in neonates and infants: a phase-contrast mRI study. Neuroimage. (2019) 185:926-33. doi: 10.1016/j.neuroimage.2018.03.020

75. Kostis JB, Moreyra AE, Amendo MT, Di Pietro J, Cosgrove N, Kuo PT. The effect of age on heart rate in subjects free of heart disease. Studies by ambulatory electrocardiography and maximal exercise stress test. Circulation. (1982) 65:141-5. doi: 10.1161/01.cir.65.1.141

76. Oshima T, Karasawa F, Okazaki Y, Wada H, Satoh T. Effects of sevoflurane on cerebral blood flow and cerebral metabolic rate of oxygen in human beings: a comparison with isoflurane. Eur J Anaesthesiol. (2003) 20:5437. doi: $10.1017 / \mathrm{s} 0265021503000863$

77. Drummond JC, Dao AV, Roth DM, Cheng CR, Atwater BI, Minokadeh A, et al. Effect of dexmedetomidine on cerebral blood flow velocity, cerebral metabolic rate, and carbon dioxide response in normal humans. Anesthesiology. (2008) 108:225-32. doi: 10.1097/01.anes.0000299576.00302.4c

78. Li M, Ratcliffe SJ, Knoll F, Wu J, Ances B, Mardini W, et al. Aging: impact upon local cerebral oxygenation and blood flow with acute isovolemic hemodilution. J Neurosurg Anesthesiol. (2006) 18:12531. doi: 10.1097/00008506-200604000-00006

79. Mitchell SJ, Scheibye-Knudsen M, Longo DL, de Cabo R. Animal models of aging research: implications for human aging and age-related diseases. Annu Rev Anim Biosci. (2015) 3:283-303. doi: 10.1146/annurev-animal-022114-110829

80. Gomes AC, Falcao-Pires I, Pires AL, Bras-Silva C, Leite-Moreira AF. Rodent models of heart failure: an updated review. Heart Fail Rev. (2013) 18:21949. doi: 10.1007/s10741-012-9305-3

81. Ross CN, Salmon AB. Aging research using the common marmoset: focus on aging interventions. Nutrition Healthy Aging. (2019) 5:97109. doi: $10.3233 /$ nha- 180046

Conflict of Interest: The authors declare that the research was conducted in the absence of any commercial or financial relationships that could be construed as a potential conflict of interest.

Copyright (c) $2020 \mathrm{Wei}$, Chen, Hou, van Zijl, Xu and Lu. This is an open-access article distributed under the terms of the Creative Commons Attribution License (CC $B Y)$. The use, distribution or reproduction in other forums is permitted, provided the original author(s) and the copyright owner(s) are credited and that the original publication in this journal is cited, in accordance with accepted academic practice. No use, distribution or reproduction is permitted which does not comply with these terms. 